\title{
On the Occasion of 85th Birthday of Prof. Sadık Kakaç
}

\author{
L. Kuddusi * \\ Istanbul Technical University, Faculty of Mechanical Engineering, \\ Mechanical Engineering Department, Gümüşsuyu, 34437, Istanbul, Turkey \\ * E-Mail: kuddusi@itu.edu.tr
}

Received 11 November 2018, Accepted 15 November 2018

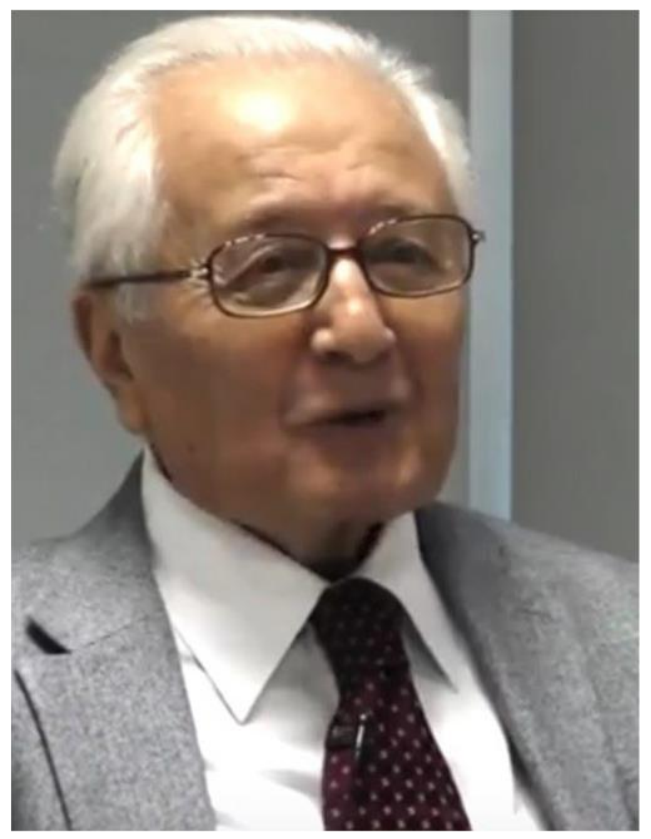

Professor Sadık Kakaç was born on October 1, 1932 in Çorum, Turkey. He received his degree of Dip. -Ing (1955) from the Department of Mechanical engineering at the Technical University of Istanbul (ITU). Professor Kakaç served as the chair of Heat Technique division as a research/teaching assistant (1955-1958) in the Department of Mechanical engineering at ITU. He continued his studies at MIT and obtained his MSc degree in Mechanical Engineering in 1959 and his MSc degree in Nuclear Engineering in 1960. With a scholarship from the UNESCO in 1963, he continued his study in $\mathrm{UK}$, and earned his PhD from the Victoria University of Manchester, UK in 1965.

Professor Kakaç started his academic career in the Department of Mechanical Engineering at the Middle East Technical University (METU) where worked between 1960 and 1982 as well as between 1998 and 1999. He was promoted to associate professor at ITU in 1967 and to full professor at METU in 1971. He served in various governmental and research organizations. He served as a member of the Turkish Atomic Energy Commission (1965-1980) and the Scientific and Technological Research Council (1972-1980). He was appointed as the Secretary General of the Turkish Atomic Energy Commission (1978-1980); representing Turkey in a number of scientific meetings abroad as a member of NATO Science Committee (1979-1980), the OECD NEA Steering Committee (1978-1980).

He served as the Chairman of the Mechanical engineering at METU (1976-1978), and then he was invited as a visiting Professor to the Department of Mechanical Engineering at the University of Miami (1980-1982), and in 1982, he was appointed as a full Professor of the mechanical engineering at the University of Miami with tenure. He served as the Chairman of the Department (1990-1998). He retired from the University of Miami in 2008 and since then he has been a Professor at TOBB University of Economics and Technology, in Ankara, Turkey.

Professor Kakaç has maintained his high quality of research for the last more than 55 years. He has authored or coauthored, publishing over 250 scientific papers on transient and steady-state laminar, turbulent forced convection heat transfer, two-phase flow instabilities, fuel-cells modeling, micro heat transfer with slip flow. Recently, Professor Kakaç has been concentrating in research on convective heat transfer enhancement with nanofluids in single-phase and two-phase flows. He has contributed significantly in all these areas and has been one of the most recognized scientists in the field of heat transfer.

Professor Kakaç has earned the highest recognition by his peers. He has received many international recognitions including Alexander von Humboldt Senior Distinguished US Scientist Award for his outstanding contributions on heat transfer and two-phase flow in 1989, Science Award by the Association of Turkish-American Scientists in 1994, ASME Heat Transfer Memorial Award in 1997. He received, Luikov Medal from International Center of Heat and Material Transfer (ICHMT) in 2015 for his contributions to the field of heat transfer; ASME HTD 75 ${ }^{\text {th }}$ Anniversary Medal, cited among 100 well known scientists in the world (2013); ASME Honorary membership in 2013 for his life time achievements.

He also received distinguished service awards from the Middle East Technical University in 1998, and from the Turkish Scientific and Technical Research Council in 2000. Professor Kakaç has received "life time achievement" award from the TOBB University of Economics and Technology (2010) and iNEER "leadership" award for his contribution to International Engineering Education and Research (2012).

Professor Kakaç received the Doctor Honoris Causa from the University of Ovidius, Romania (1998), the University of Reims, France (1999), and Odessa State Academy of refrigeration (2007). He is a member of the Turkish Academy of Sciences (1999), and a foreign member of the Academy of Sciences of the Republic of Bashkortostan of Russian Federation (1998), and the Brazilian Academy of Sciences (2012). He is honorary Professor of Shanghai Institute of Electrical Power (1986), Xi'an Jiaotong University (1988) China, and the Engineering College at the Ghandi Institute of Technology and Management, India (1992). He is a Fellow member of ASME, a member of the Scientific Council, and the Executive Committee, and Fellow of the ICHMT. 
Professor Kakaç has organized and directed conferences and summer schools for the NATO Advanced Study Institutes on various topics of thermal and fluid sciences for the last 35 years bringing the eminent scientists as lecturers and the young scientists together from NATO and non-NATO countries. Professor Kakaç has been frequently invited as lecturer and speaker by various institutions in US, Europe, China, Malaysia, Singapore, Brazil and other countries; he organized short courses on Heat Exchangers thermal design in Taiwan, Singapore, Thailand, France and Turkey.

Professor Kakaç has been serving as editor or in editorial board of major journals on heat mass transfer and energy journals. He is the author or co- author of very popular text books of Convective Heat Transfer, Heat Conduction and Thermal Design of Heat Exchangers; he edited 28 volumes in the field of thermal sciences - fundamentals and design, including the Handbook of Single-Phase Convective Heat Transfer, and Boilers, Evaporators and Condensers which all became permanent reference books in the field.

A very recent work of Professor Kakaç related with the history of thermodynamics "DEVELOPMENT OF THE SCIENCE OF THERMODYNAMICS" is published in Journal of Engineering Physics and Thermophysics, Vol. 90, No. 4, July, 2017. In his work he explains the history of discovery of three basic laws of thermodynamics and their formulations. This major work starts with Sadi Carnot (1796-1832) as the initiator of Thermodynamics. It continues with the works of Emile Clapeyron (1799-1864), Rudolf Clausius (1822-1888), William Thomson (later Lord Kelvin, 1824-1907). He also explains the famous experiments of James Prescott Joule (1818-1889) that led to the first law of thermodynamics for a cyclic process in a closed system. The first law of thermodynamics was later expressed in an explicit form.

Professor Kakaç also recalls Daniel Gabriel Fahrenheit a German physicist, engineer, and glass blower, who had already invented the mercury-in-glass thermometer in 1714 and proposed a temperature scale which was named after him.

Professor Kakaç in his pioneering paper explains the discovery of the second law of thermodynamics. He says, the second law of thermodynamics, as expressed by Planck, is known in modern thermodynamics as the Planck-Kelvin statement. He also states the other statement of the second law of thermodynamics expressed by Clausius. According to the Clausius statement of the second law of thermodynamics, "it is impossible to construct a device which operates on a cycle and produces no other effect than the transfer of heat from a cooler body to a hotter body.". Professor Kakaç then talks of Josiah Willard Gibbs (1839-1903) who started from the Clausius laws according to which "the energy of the universe is constant, the entropy of the universe tends to maximum.".

Professor Kakaç states that the third law of thermodynamics has been first formulated by German chemist and physicist Walther Nernst (1864-1941). In his book "A Survey of Thermodynamics" (American Institute of Physics, 1994), Martin Bailyn quotes the Nernst's statement of the third law as "It is impossible for any procedure to lead to the isotherm $T=0$ in a finite number of steps." This essentially establishes a temperature of absolute zero as being unattainable by analogy with the speed of light. Professor Kakaç explains the works of Anne Rooney, Robert Boyle, Johann Heinrich Lambert and Siabal Mitra, which are related with the third law of thermodynamics.

Professor Kakaç also acknowledges the contributions of Robert Mayer and Jean Baptiste Joseph Fourier in the development of thermodynamics as science and Joseph H. Keenan (1900-1977) in the teaching of thermodynamics. He created the MIT School of thermodynamics and published the book "Thermodynamics" (1941) that covers the fundamentals of thermodynamics with applications in mechanical and chemical engineering. He is a coauthor of "Thermodynamic Properties of Steam" (1936), a basic source of data for design in thermal engineering, which is of great importance in the steam-power industry. "Thermodynamic Properties of Air" (1945) and "Gas Tables" (1948), prepared by Keenan and Kaye.

Professor Kakaç acknowledges a well-known scientist Adrian Bejan (1948) from the Keenan MIT school who clarified the use of the second-law analysis in the thermal design of energy systems and optimization. He made the availability (exergy) analysis a popular thermodynamic tool under the title the second-law analysis. Professor Kakaç also acknowledges of discovery of the constructal law as a new law of physics by Bejan, which states that "for a finite-size flow system to persist in time (to live), it must evolve in such a way that it provides easier access to the imposed (global) currents that flow through it." According to this law, the changes in a configuration must occur in a particular direction in time; design in nature is not static, but dynamic and evolving.

We congratulate Professor Kakaç on the occasion of his 85th birthday. We wish a healthy long life for Professor Kakaç. It is our belief that his contribution to the fields of heat transfer and thermodynamics will continue. Thanks a lot Professor Kakaç. 